\title{
POSSIBILITY OF CONTROL OF PAINTED APPLE MOTH (TEIA ANARTOIDES) USING SINGLE COMPONENT MATING DISRUPTION
}

\author{
D.M. SUCKLING ${ }^{1}$, J.G. CHARLES ${ }^{2}$, D. ALLEN ${ }^{2}$ and P.S. STEVENS ${ }^{2}$
}

\author{
${ }^{1}$ HortResearch, PO Box 51, Lincoln \\ ${ }^{2}$ HortResearch, Private Bag 92 169, Auckland \\ Corresponding author: msuckling@hortresearch.co.nz
}

\begin{abstract}
Disruption of mate location by painted apple moth males was tested using two 3M sprayable formulations of Z6-heneicosen-11-one applied in field cages at Glendene, Auckland. Four Acacia branches were installed upright in each field cage and the sprays were applied at $50 \mu$ l pheromone in 1 litre of water to the foliage and walls. A third field cage, located upwind, was left untreated. Up to $50 \%$ of males located virgin female moths in the control cage, compared to very low or zero in the cages treated with sprayable pheromone. The test indicates that single component mating disruption of painted apple moth is a potentially useful tactic that warrants small plot testing and further evaluation of feasibility. The legislative constraints to the development of this technology are discussed.

Keywords: mating disruption, pheromone, biosecurity, Lymantriidae.
\end{abstract}

\section{INTRODUCTION}

Painted apple moth, Teia anartoides Walker (Lepidoptera: Lymantriidae), is an Australian pest of horticulture and forestry, and has been the subject of an eradication programme in Auckland by MAF Biosecurity Authority since 1999. Options for dealing with moth pest incursions are limited to existing technologies (e.g. spraying insecticide), but the identification of the pheromone could provide a powerful tool to assist the eradication programme. Although pheromone identification can sometimes be rapid, for some moth species it is more difficult. In the case of the guava moth, Coscioptycha improbana Meyrick(Lepidoptera: Carposinidae), another Australian native moth recently arrived in New Zealand, the pheromone identification was completed within a very few months (A.R. Gibb, unpubl. data). However, the pheromone for $T$. anartoides is proving to be very difficult to establish, and the identification of all the components in an attractive blend has not yet been completed.

Pheromone traps are a recognised tool for pest monitoring and can be used for determining the effectiveness of control tactics, establishing the geographic distribution and also providing technologies for direct control (e.g. Sharov et al. 2002). Pheromone traps are the basis for routine pro-active gypsy moth trapping around ports and airports in New Zealand. Direct control tactics using pheromones against moth pests (including the Lymantriidae) include the options of mating disruption, mass trapping or lure and kill (Suckling \& Karg 2000). Technologies such as mass trapping or lure and kill require an attractive pheromone blend. Lure and kill (Suckling \& Karg 2000) also involves the use of insecticide as the killing agent and would face significant logistic and registration hurdles, especially for use in an urban environment.

An attractive sex pheromone blend of painted apple moth had yet to be identified at the time of the work reported here, although Z6-heneicosen-11-one was identified by the HortResearch team (D.M. Suckling, unpubl. data) as a major component of pheromone glands, as is the case in the related Orgyia species. Mating disruption without an attractive synthetic pheromone has been achieved previously (e.g. Suckling \& Burnip 1996), and was considered worthy of investigation as a potentially useful adjunct for eradication or control of painted apple moth. This would be particularly useful in forested areas where 
insecticides or biopesticides could face coverage problems. Single pheromone components have been shown to be equally disruptive to the fully attractive blend in a number of cases. Importantly, Z6-heneicosen-11-one has been shown to be highly effective for disruption of Douglas fir tussock moth (DFTM), Orgyia pseudosugata (Hulme \& Gray 1994, 1996). This compound was successfully tested at rates of $20-75 \mathrm{~g} / \mathrm{ha}$ in a Canadian forest using a polyvinyl chloride bead formulation. The disruption of trapping lasted up to one year (Gray \& Hulme 1996). In that study ground application was found to be more effective than aerial application.

A commercial formulation research project on sprayable moth sex pheromones for $3 \mathrm{M}$ Canada gave us access to the new technology necessary for such an approach. The 3M pheromones formulations degrade in the environment and several are now registered in USA. The micro-encapsulation product is typically applied at 25-50 g ai of pheromone/ha. The potential environmental and human health impact of such sprayable pheromones would appear to be negligible, since the active ingredient could be expected to be present in parts per billion in the air (Suckling et al. 1999). Similar formulations are permitted in USA on fruit crops.

Waitakere City Council and the Agricultural Compounds and Veterinary Medicines Group (ACVM) gave permission for a field cage scale test conducted at Harmel Reserve. The legal status of sprayable pheromones for mating disruption was somewhat unclear, although their status was changed to being a pesticide with the new legislative framework of the Hazardous Substances and New Organisms Act. The lack of residues on food crops from potential application in a forestry context meant that the ACVM did not have jurisdiction. The general status of sprayable sex pheromones was also discussed with $\mathrm{Dr}$ Don Hannah (Environmental Risk Management Authority, ERMA). The approach taken here of containing the test in a field cage, was considered to be a laboratory scale test. This was dictated by the lack of an experimental use permit for the sprayable pheromone, and a lack of clarity in the legislative framework as to the need for a permit at all.

The aim of this test was to examine the potential for single component mating disruption as a tactic to manage or eradicate painted apple moth. The approach taken was to compare the behaviour and orientation of males in a temporary field cage towards virgin females, both with and without a background of Z6-heneicosen-11-one applied to the cloth walls and to Acacia branches and foliage.

\section{MATERIALS AND METHODS}

Three treatments were compared (Control, DFTM-1 and DFTM-2). The two DFTM pheromone formulations were similar to $3 \mathrm{M}$ sprayable pheromone formulations previously registered by the Environmental Protection Agency in USA. The trial was conducted at a grassy area adjacent to trees at Harmel Reserve, Glendene, which is inside the known distribution of painted apple moth. Tests were conducted on $19 \& 26$ April 2001, between 12:00 am and 3:30 pm.

Male moths ( 24 or $48 \mathrm{~h}$ old) were placed into $50 \mathrm{ml}$ sealed screw cap tubes in the early morning. Three field cages ( 4 × $3 \times 2 \mathrm{~m}, 30 \mathrm{~m}$ apart) were set up, each with a roof and insect-proof screen walls (gazebo type, "The Warehouse", Christchurch). To ensure that there was no cross contamination between treatments on the two dates, the same cages were used for the same treatments in both trials. Between replicates the gazebos were transported in separate vehicles and stored in separate rooms to minimise the risk of contamination. Four $1.5 \mathrm{~m}$ tall Acacia branches were cut and staked upright over the grass in each gazebo. In the two pheromone treatments (downwind of the control), the Acacia foliage and gazebo walls were sprayed with a total of 1 litre of aqueous $3 \mathrm{M}$ sprayable pheromone $(0.5 \mathrm{ml}$ of $10 \%$ ai per litre or $50 \mu \mathrm{l}$ pheromone active ingredient per cage). After 20 minutes drying time, three newly-emerged virgin female moths were placed in $50 \mathrm{ml}$ gauze cages as the lures, and suspended at $1.5 \mathrm{~m}$ high from a string, $30-50 \mathrm{~cm}$ from the upwind end of each gazebo. A relatively consistent sea breeze (est. 10 knots) into the "upwind" edge of each gazebo was present, although some turbulence, gusting and temporary change of wind direction was noted. 
Behavioural assessment was conducted initially in the control, with all three observers present in order to provide consistency in methodology. After 12:00 am, males were released individually by opening $50 \mathrm{ml}$ sample vials on a tray held at $1.5 \mathrm{~m}$ height and downwind at a distance of $1.5 \mathrm{~m}$ from the females. Moth behaviour was observed and recorded for $3 \mathrm{~min}$. Males were re-caught and re-tubed after each release $(\mathrm{n}=20-30$ per treatment). At the end of the day, all moths were collected and removed from the field. The behaviour was recorded as 0 - no behaviour, 1 - activation/wing fanning, upwind flight, 3 - zig zag flight orientation to females and 4 - landing. Behavioural scores were then calculated for the highest behavioural category shown by individual moths. The tests on the two dates were essentially replicates, but the differences in moth behaviour in the controls have led us to avoid pooling these results.

\section{RESULTS AND DISCUSSION}

Close range visual observation of female moths showed pumping of the abdomen typical of the release of pheromones and "calling" behaviour. Wild male moths were observed approaching the control cage from the exterior, out of the Acacia forest margin, confirming that the virgin females were actively calling. The male success at female location in the $3 \mathrm{~min}$ allowed was $50 \%$ in the control $(n=29), 0 \%$ for DFTM-2 $(n=20)$ and $15 \%$ for DFTM-1 $(n=20)$ on 19 April. The mean behavioural score in the control field cage was 2.93 out of a possible top score of 4.00 (if all males had contacted the female cages) (Fig. 1a). When data from the two pheromone treatments (containing the same active ingredient) were combined, a significant difference in male success at female location was present between the control and pheromone treatments $\left(\chi^{2}=5.8, \mathrm{df}=1\right.$, $\mathrm{P}<0.05)$. There was a low frequency of control males $(17 \%)$ that reached activation as
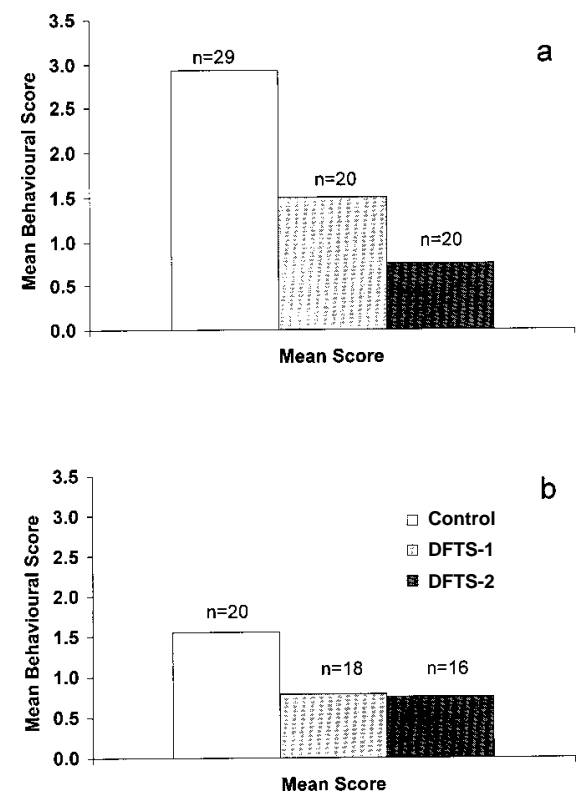

FIGURE 1: Mean behavioural score of male painted apple moths responding to virgin female moths released in a gazebo with no pheromone or treated with $50 \mu \mathrm{l}$ of sprayable Douglas fir tussock moth pheromone in one of two formulations (DFTM -1 or DFTM-2). (a) 19 April. (b) 26 April. 
their highest behavioural state, compared to the two pheromone treatments, in which $65-80 \%$ of moths went no further (Fig. 2a). This difference in activation between control and combined pheromone treatments was highly significant $\left(\chi^{2}=20.5\right.$, $\left.\mathrm{df}=1, \mathrm{P}<0.001\right)$.

On the second test date (26 April), the mean behavioural score for control males was disappointingly low (Fig. 1b), possibly due to the age of males used ( $<24 \mathrm{~h}$ old) or to potential prior exposure of the males to pheromone contamination from the gazebos used earlier, despite considerable care to avoid this. Twenty percent of control males showed no response at all, and only $10 \%$ of males actually contacted cages with females inside, compared with $50 \%$ in the earlier test. However, in the pheromone treatments the behavioural outcomes were similar in ratio to the previous results (Fig. 2b), with the activation stage being the highest behavioural category state shown. While a lower proportion of control insects responded on the second date, test results on both dates clearly showed successful disruption of male moth orientation in the presence of a single component sprayable sex pheromone.

These tests were conducted in a field cage, and therefore are subject to such difficulties as variation in wind speed during the experiment. Further repeats of the test were not conducted due to the season and because larger scale field tests were considered necessary to progress the method.
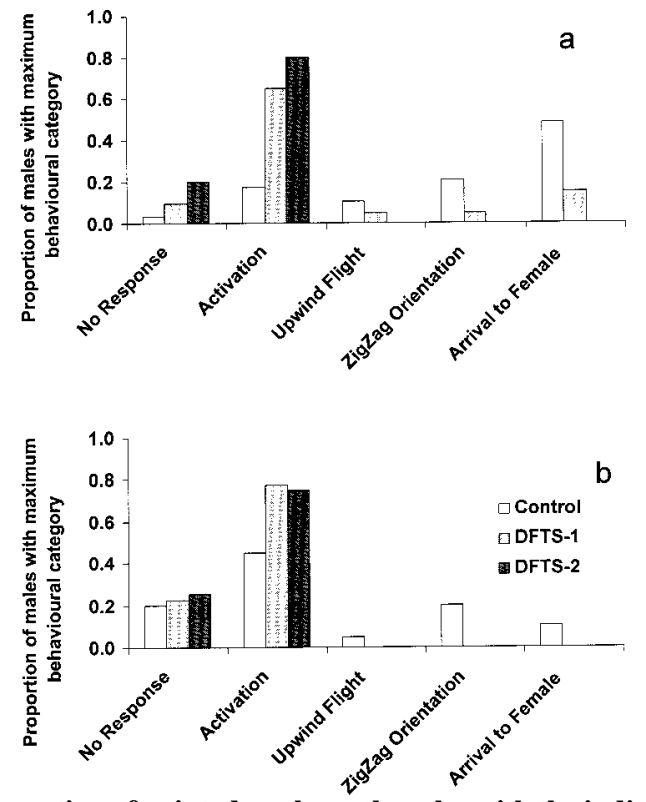

FIGURE 2: Proportion of painted apple moth males with the indicated maximum behavioural response to virgin female moths in a gazebo with no pheromone or treated with $50 \mu \mathrm{l}$ of sprayable Douglas fir tussock moth pheromone in one of two formulations (DFTM -1 or DFTM-2). (a) 19 April. (b) 26 April.

These preliminary results were presented to the Painted Apple Moth Technical Advisory Group in May 2001. The minuted consensus of that meeting was that further development of this approach was warranted. The results were also presented to Dr Sandy Leibhold (USDA, MA) during the independent Painted Apple Moth Review (Liebold \& Simpson 2001), who responded with an encouraging discussion on the use of mating disruption in the gyspy moth "slow to spread" programme in USA (e.g. Sharov et al. 2002). 
Current OECD guidelines recommend fast tracking registration of straight chain Lepidopteran sex pheromones (OECD 2001) because the atmospheric concentrations involved are very low (parts per billion or lower), they have an inherent lack of toxicity $(>5000 \mathrm{mg} / \mathrm{kg}$ ), they are successfully replacing undesirable broad-spectrum insecticides and they do not persist in the environment. However, in New Zealand, the changing legislative framework for agricultural compounds and hazardous substances of all types created considerable unease in the legal status of the new approach. The uncertainty was exacerbated by two factors. Firstly there is no local precedent for the use of pheromones on this scale in an urban setting, and secondly there is a no specific information about the environmental and human health risks associated with the pheromone compound of interest. The lack of any evidence of harmful aspects of moth sex pheromones internationally (OECD 2001) was apparently not sufficient to satisfy the requirements of the HSNO Act.

Discussions with the senior scientist at ERMA, followed by use of the self-assessment form (Anon. 2000) indicated that it was unclear whether the HSNO Act would be applicable to mating disruption. This was due to the lack of toxicological information on the specific pheromone compound. In the light of this uncertainty, and in order to avoid potential prosecution under the new Act, the authors decided to await further guidance from MAF Biosecurity before proceeding with any further tests of mating disruption. No solution has been developed to this legislative impasse, so the mating disruption against painted apple moth has not been further developed.

Legislative issues aside, the tests reported here indicate that single component mating disruption of painted apple moth is a potentially useful tactic that warrants large plot testing and further evaluation of feasibility. Positive results support a decision to conduct a proper field trial, and such a trial would be much more valuable in showing efficacy than the reported caged trials. Additional investigation will need to consider the environmental impact of sprayable pheromones, their likely cost and overall appropriateness for the eradication or control of this insect. While mating disruption has never been used in insect eradication previously, the powerful track record of this technology against many species of Lepidoptera internationally suggests that it deserves more thorough examination.

\section{ACKNOWLEDGEMENTS}

We would like to thank Anne Barrington for providing insects for the trial. This work was funded by the Foundation for Research, Science and Technology (COX0004). We would like to thank Howard Wearing and Sandy Liebold for constructive comments.

\section{REFERENCES}

Anon. 2002: www.ermanz.govt.nz (20/05/02).

Gray, T.; Hulme, M. 1995: Mating disruption of Douglas-fir tussock moth one and two years after the application of pheromone. J. Entomol. Soc. Brit. Columbia 92: 101105.

Hulme, M.; Gray, T. 1994: Mating disruption of Douglas-fir tussock moth ((Lepidoptera: Lymantriidae) using a sprayable bead formulation of Z6-heinecosen-11-one. Environ. Entomol. 23: 1097-1100.

Hulme, M.; Gray, T. 1996: Effect of pheromone dosage on the mating disruption of Douglas-fir tussock moth . J. Entomol. Soc. Brit. Columbia 93: 99-103.

Leibhold, A.; Simpson, B. 2001: Report on a review of the response of the Ministry of Agriculture and Forestry to the incursion of the painted apple moth, Teia anartoides. MAF, Wellington, New Zealand.

O.E.C.D. 2001: Guidance for Registration Requirements for Pheromones and Other Semiochemicals Used for Arthropod Pest Control. OECD Environment, Health and Safety Publications, Paris. Series on Pesticides No. 12.

Sharov, A.A.; Leonard, D. Liebhold, A.M.; Clemens, N.S. 2002: Evaluation of preventive treatments in low-density gypsy moth populations. J. Econ. Entomol.: In press. 


\section{Biosecurity}

Suckling, D.M.; Karg, G. 2000: Pheromones and semiochemicals. In: Biological and Biotechnical Control of Insect Pests. Rechcigl. J.; Rechcigl, N. ed. CRC Press, Boca Raton. Pp. 63-99.

Suckling, D.M.; Burnip, G.M. 1996: Orientation and mating disruption in Planotortrix octo using pheromone and inhibitor. Entomol. Exp. Appl. 78: 149-158.

Suckling, D.M.; Green, S.R.; Gibb, A.R; Karg, G. 1999: Predicting atmospheric concentration of pheromone in treated apple orchards. J. Chem. Ecol. 25: 117-139. 